\title{
DESAFIOS À UNIVERSIDADE NESTE TERCEIRO MILÉNIO *
}

\section{Célia Ribeiro**}

\begin{abstract}
Este artigo apresenta algumas das alterações e consequentes desafios que se colocam actualmente ao ensino superior universitário, com destaque para os decorrentes do Processo de Bolonha e da sociedade da informação $e$ do conhecimento, assinalam-se as implicações para o processo de ensino $e$ aprendizagem, especificamente na modificação do papel do discente e na importância da formação pedagógica do docente.
\end{abstract}

Palavras-chave: Processo de Bolonha, sociedade da informação e do conhecimento, ensino e aprendizagem.

"O artigo que ora se publica, com ligeiras adaptações, é parte integrante da
Dissertação de Doutoramento em Psicologia, apresentada a Faculdade de Psicologia e
de Ciências da Educação da Universidade de Coimbra, a qual foi elaborada sob a
orientação do Prof. Doutor Nicolau de Almeida Vasconcelos Raposo.

"** Departamento de Economia, Gestão e Ciências Sociais da Universidade Católica Portuguesa 


\section{INTRODUÇÃO}

No discurso de abertura da Conferência Mundial sobre Educação Superior, no dia 5 de Outubro de 1998, Frederico Mayor, então directorgeral da UNESCO, referiu que o sector universitário do século XXI será responsável pela formação de cidadãos que saibam fazer o melhor uso possível da sua liberdade. Esta liberdade refere-se à chegada de uma genuína democracia, que só poderá acontecer com o auxílio do ensino superior.

As instituições de ensino superior e em particular, a universidade, confrontam-se, hoje, com um grande número de questões que exigem respostas inovadoras e mudanças substanciais nos modelos académicos tradicionais. Segundo Santiago (2000: 179), de entre esses problemas, alguns colocam desafios profundos à estratégia e organização das actividades destas instituições, a saber: a dificuldade em responder às expectativas dos diferentes grupos sociais a propósito das funções do ensino superior; as alterações nos esquemas de financiamento (Amaral, 1995; Thys-Clement, 1998); o aumento e a diversidade da população estudantil (Santiago, 1997; Goedegebuure \& Meek, 1998); a dinâmica do desenvolvimento do conhecimento científico que induz uma maior especialização disciplinar (Clark, 1983, 1996; Lorange, 1996) e a consequente fragmentação organizacional, que acarreta desafios suplementares de gestão e de organização; a cultura académica fundada na tradição da disciplina base (Lorange, 1996), na formalização excessiva das estruturas e na insularidade, excessivamente centradas nelas próprias (Smith, 1996) e bastante avessas a mudanças e aberturas ao exterior; os obstáculos à comunicação interna; a falta de estratégias e de instrumentos de avaliação das actividades que permita a monitorização de processos e a análise sistemática do impacto das decisões; a gestão do paradoxo da necessidade de autonomia profissional dos actores académicos para atingir a eficácia (Mintzeberg, 1994; Conceição, Durão, Heitor et al., 1998) versus o princípio da sua responsabilização face às expectativas da sociedade, a qual pressupõe uma maior formalização de normas para o controlo dos seus desempenhos (in Santiago, 2000: 179) ${ }^{1}$, escassez de emprego e as novas configurações do trabalho.

Para além das mudanças referidas e da necessidade de se encontrarem respostas eficazes em tempo útil, podemos ainda identificar desafios contemporâneos colocados à universidade decorrentes do Processo de Bolonha e da sociedade da informação e do conhecimento, que passaremos a explicitar. 


\section{OS DESAFIOS À UNIVERSIDADE DECORRENTES DO PROCESSO DE BOLONHA}

Grande parte das discussões que actualmente se realizam em torno do ensino superior referem o Processo de Bolonha. Mas de que trata o Processo de Bolonha?

O Processo de criação da Área Europeia do Ensino Superior é vulgarmente conhecido por Processo de Bolonha e tem como base uma Declaração assinada pelos Ministros responsáveis pelo ensino superior de 28 países europeus (Alemanha, Áustria, Bélgica, Bulgária, Dinamarca, Espanha, Eslováquia, Eslovénia, Finlândia, França, Grécia, Hungria, Islândia, Irlanda, Itália, Letónia, Lituânia, Luxemburgo, Malta, Países Baixos, Noruega, Polónia, Portugal, Reino Unido, Roménia, República Checa, Suécia, Suiça) a 19 de Junho de 1999, na sequência da assinatura da Declaração da Sorbonne, em Maio de 1998, por um número limitado de países ${ }^{2}$.

Uma declaração que, na primeira conferência de acompanhamento, que teve lugar em Praga a 19 de Maio de 2001, foi aumentado o número de objectivos e reafirmado o compromisso em estabelecer a Área Europeia de Ensino Superior até 2010. A 19 de Setembro de 2003, os Ministros responsáveis pelo Ensino Superior de 33 países Europeus encontraram-se em Berlim para rever o progresso alcançado e estabelecer prioridades e novos objectivos para os próximos anos, com vista a acelerar a construção da Área Europeia de Ensino Superior, passou-se a falar do Processo de Bolonha, estreitamente associado ao desenvolvimento de uma economia baseada no conhecimento.

A Declaração assinada em Bolonha, intitulada The European Higher Education Area, conhecida simplesmente como Declaração de Bolonha, tem como objectivo central essa construção ${ }^{3}$, possibilitando "um grande salto qualitativo na cooperação entre os diversos sistemas nacionais do ensino superior, originando um processo dinâmico que tem vindo a actuar como catalisador quer de reformas nacionais que se encontravam já em curso em 1999, por exemplo, na Alemanha, França e Itália, quer de reformas entretanto iniciadas na maioria dos restantes países signatários" (Simão, Santos \& Costa, 2002: 245) ${ }^{4}$.

Partindo dos objectivos gerais de mobilidade ${ }^{5}$, de empregabilidade ${ }^{6}$ dos diplomados e de competitividade dos sistemas europeus de ensino superior, esta declaração define seis objectivos específicos, entre os quais se contam a inteligibilidade e comparabilidade dos graus conferidos nos sistemas europeus de ensino superior. Além disso, avança para a estruturação dos graus académicos em dois ciclos, de graduação e pósgraduação, sendo que o acesso ao segundo ciclo pressupõe completar um ciclo com a duração mínima de três anos. 
Bolonha generaliza assim duas novas concepções educativas de grande importância: a primeira refere-se à estrutura dos cursos, que deverá ser concebida na perspectiva daquele que aprende e não daquele que ensina; a segunda é de que a formação inicial deverá conferir ao estudante uma capacidade progressiva de ingresso no mundo do trabalho (Araújo, 2002) ${ }^{7}$.

$O$ primeiro aspecto traduz uma mudança de paradigma de ensino/aprendizagem: o enfoque desloca-se do ensino para a aprendizagem; a contabilização das horas necessárias à obtenção de um grau académico não terá mais em conta a prestação da docência, mas sim o esforço de aprendizagem despendido pelo discente. E é sujeita a um limite/semestre igual para todos os estudantes, independente da licenciatura que frequentam. Na prática, tal significa que caberá também ao docente o papel de orientador de estudo/tutor e que o estudante dedicará grande parte do seu tempo, por exemplo, na biblioteca, a estudar (Araújo, 2002).

$\mathrm{O}$ segundo incentiva o estudante a construir o seu percurso de formação, intercalando formação académica e formação em exercício. Preconiza-se que após o primeiro ciclo (que deverá ser tão curto quanto possível e concebido por forma a que confira um certo grau de competência profissional), o jovem possa confrontar-se com as ofertas do mundo do trabalho e optar por uma via profissional. Neste contexto, mais tarde ou mais cedo se justificará o regresso à formação académica e a opção por uma pós-graduação pertinente. Isto não exclui que outros jovens optem por uma formação continuada, objectivada no doutoramento e perspectivada para actuação nas esferas académica e científica (Araújo, 2002) ${ }^{8}$.

Especificamos de seguida algumas características essenciais deste "projecto" que é a Declaração de Bolonha.

A sua peça central é o "quadro comum de referência para qualificações" que deve ser esclarecido (Haug, 2001). Em primeiro lugar, deve salientar-se que não se trata de um instrumento de uniformização dos currículos ${ }^{9}$, das instituições ou dos diplomas. Em segundo lugar, refere-se a "qualificações", não a "graus"; a Declaração tem uma forte tendência para o emprego e para a dimensão do mercado de trabalho, mais do que para os aspectos mais "académicos". Por outro lado, o quadro reporta-se a todas as qualificações do ensino superior, incluindo universidades, colleges/politécnicos e a aprendizagem ao longo da vida. Além disso, refere-se a "qualificações", não a instituições: o que importa não é onde uma qualificação foi adquirida, mas que aptidões e que competências ela garante. 
No que diz respeito à situação portuguesa, o sistema de ensino superior prevê a existência de dois níveis distintos de graduação: bacharelato e licenciatura. «O Conselho Nacional de Educação aprovou, em 1993 e 1995, pareceres que apontam para o desaparecimento destes graus, substituindo-os por um "Diploma de Estudos Superiores", o que significa que a discussão sobre os graus de ensino superior hoje suscitada pela avaliação das implicações a nível nacional, pela Declaração de Bolonha, não é nova e é, de facto, ressuscitada num novo contexto» (Revista do SNESup, 2002).

Também o Parecer Geral da Universidade Católica Portuguesa sobre a Declaração de Bolonha refere que o principal problema que se coloca em Portugal é o da redução do número de graus, de quatro para três. "Apesar do grau que tradicionalmente se identificou com os objectivos de uma formação curta para mais rápido ingresso no mercado de trabalho ser o de bacharelato, contudo, foi o de licenciatura que vingou, na cultura universitária portuguesa" (s.d., ponto II), como aquele que confere um estatuto socialmente reconhecido. Assim, a sugestão recai sobre a eliminação do bacharelato e a adopção da licenciatura como primeiro grau do sistema de ensino superior, entendendo a licenciatura de forma não especializada, deixando as especializações para as pós-graduações.

De acordo com o mesmo parecer, "a duração da formação inicial para este primeiro ciclo não pode deixar de atender ao nível que os estudantes trazem do secundário. E não deve visar apenas a formação profissional, mas também a formação cultural dos estudantes" (s.d., ponto II) $)^{10}$.

Pelo exposto, a Declaração de Bolonha exige, a nível da organização pedagógica, que os percursos escolares se tornem mais flexíveis; o ensino deve deixar de ser predominantemente magistral para os discentes, cada vez mais heterogéneos, valorizando, não só os conteúdos cognitivos de cada disciplina, mas, igualmente, as capacidades e competências transversais (como o desenvolvimento do raciocínio crítico, a capacidade para tomar decisões e resolver problemas, capacidades de comunicação, de liderança, de inovação, de trabalho em equipa, de promoção e adaptação à mudança, entre outros aspectos); desta forma, as metodologias de ensino/aprendizagem deverão ser modificadas e diversificadas.

É de referir, neste sentido, as consequências da introdução de um sistema de créditos do tipo ECTS (European Credit Transfer System). Embora já exista em Portugal um sistema de créditos, apesar de não estar generalizado a todos os subsistemas, instituições e cursos, que mede as componentes do ensino presencial - aulas teóricas, teórico-práticas, práticas, laboratoriais, seminários -, "reflectindo a lógica de um ensino disciplinar baseado essencialmente numa transmissão de conhecimentos 
em que o estudante é sujeito relativamente passivo. O sistema de ECTS introduz um novo paradigma da organização do ensino, centrado no estudante e nos objectivos da formação ${ }^{11}$. Ao medir o esforço (a "carga total de trabalho») do estudante, coloca o enfoque na aprendizagem, centra a formação no estudante, como sujeito activo no processo de aprendizagem, e orienta a formação para objectivos predefinidos. A sua aplicação pressupõe, pois, uma definição prévia dos saberes a serem adquiridos - os conhecimentos gerais e específicos e as competências, atitudes e valores" (Simão, Santos \& Costa, 2002: 257-258).

\section{OS DESAFIOS PERANTE A SOCIEDADE DA INFORMAÇÃO E DO CONHECIMENTO}

Começamos por partilhar com o Relatório para a UNESCO os quatro pilares do conhecimento ao longo de toda a vida e de que, em especial, a educação se deve ocupar, constituindo as aprendizagens fundamentais: "aprender a conhecer, isto é adquirir os instrumentos da compreensão; aprender a fazer, para poder agir sobre o meio envolvente; aprender a viver juntos, a fim de participar e cooperar com os outros em todas as actividades humanas; finalmente aprender a ser, via essencial que integra as três precedentes" (Delors, ${ }^{5}$ 1999: 77).

Tão importante quanto esta afirmação de princípio, é aquela que considera que o ensino formal se vem orientando essencialmente para 0 "aprender a conhecer" e, em menor escala, para o "aprender a fazer". É também de realçar a preocupação da comissão para que cada um dos quatro pilares do conhecimento deva ser "objecto de atenção igual por parte do ensino estruturado, a fim de que a educação apareça como uma experiência global a levar a cabo ao longo de toda uma vida, no plano cognitivo e prático, para o indivíduo enquanto pessoa e membro da sociedade" (Delors, ${ }^{5}$ 1999: 78).

É ainda explícita a recomendação da OCDE a este respeito: "Numa altura em que os sistemas educativos formais tendem a privilegiar $o$ acesso ao conhecimento, em detrimento de outras formas de aprendizagem, importa conceber a educação como um todo. Esta perspectiva deve, de futuro, inspirar è orientar as reformas educativas, tanto a nível da elaboração de programas como da definição de novas políticas pedagógicas" (Delors, ${ }^{5} 1999$ : 88). Posto isto, fica claro que se torna urgente preparar os agentes educativos para esta mudança do conceito abrangente de educação, dos seus princípios e das suas finalidades. $\mathrm{Na}$ actualidade, constatamos uma transformação da sociedade para a economia do conhecimento com base no domínio de competências muito ligadas ao investimento na tecnologia. Por exemplo, em 1995, foi 
divulgado o relatório do Grupo de Trabalho da Educação da European Round Table (ERT), no qual se expressavam as grandes preocupações sociais, e se esboçavam algumas perspectivas para acompanhar os grandes blocos económicos (nomeadamente o Japão e os Estados Unidos).

No quadro síntese que a seguir se apresenta, podemos constatar ao nível do discurso, que os documentos em observação propõem um conjunto de vocábulos que tipificam as diferenças das duas sociedades: a que temos e a que teremos.

Quadro 1: Diferenças entre "duas sociedades"

\begin{tabular}{|l|l|}
\hline $\begin{array}{l}\text { O que se valoriza na sociedade } \\
\text { anterior }\end{array}$ & $\begin{array}{l}\text { O que se valoriza na sociedade do } \\
\text { conhecimento }\end{array}$ \\
\hline Saberes & Competências \\
Fixação & Mobilidade/circulação \\
Regulamentação & Concorrência \\
Culturas hegemónicas & Globalização \\
Adaptação & Transformação \\
Hierarquização & Responsabilização \\
Diploma/qualificação & Competência pessoal \\
Exclusão & Integração \\
Tradição & Redefinição de valores \\
\hline
\end{tabular}

A mudança urgente dos sistemas educativos na Europa foi exemplarmente exigida, na cimeira da ERT, pelos industriais que se interrogavam sobre as adaptações globais fundamentais a introduzir nesses sistemas de modo a fazer-se face aos desafios económicos e sociais mundiais.

As mudanças que afectam a sociedade em geral e a escola em particular conduzem a Europa à definição de políticas e respectivas estratégias no sentido de uma adaptação a uma nova realidade e a uma nova concepção de conhecimento ${ }^{12}$, trata-se, no fundo, da transição para a sociedade do futuro.

O desenvolvimento profissional dos docentes encontra-se actualmente muito associado à pesquisa, tratamento de informação e alargamento de fontes de informação, o que, há alguns anos atrás, era impensável. Sem menosprezar outras estratégias, é-lhes permitido utilizar metodologias activas em sala de aula, co-responsabilizar os alunos mais ou menos pelo seu percurso de aprendizagem, diversificar estratégias, individualizar actividades de ensino/aprendizagem e recorrer a novas formas de motivação para a aprendizagem. Realmente, desde 1994, a World Wide 
Web e os recursos relacionados com a Internet (e.g., e-mail, chat, grupos de discussão) têm se transformado gradualmente num componente importante da pedagogia do ensino superior dando origem a diversas investigações neste âmbito (e.g., Schutte, 2002).

\section{QUE DESAFIOS PARA O ENSINO E A APRENDIZAGEM?}

É de destacar a necessária adaptação da organização das instituições de ensino superior aos percursos de aprendizagem e de formação dos estudantes que correspondem cada vez menos ao perfil tradicional de discente universitário. A referência ao paradigma da aprendizagem ao longo da vida terá consequências variadas e nomeadamente: a) no reconhecimento, à chegada, de formações e competências dos estudantes; b) na organização espácio-temporal das formações; c) na comparabilidade das qualificações e mobilidade de discentes; d) na avaliação da «quantidade e qualidade» das aprendizagens realizadas; e) não menos relevante na empregabilidade dos diplomados (Pinto, 2003) ${ }^{13}$.

Todas estas alterações têm assim implicações nas práticas de ensino e no processo de aprendizagem, que por sua vez deverão tornar-se mais activas, cooperativas e participativas e que facilitem a aquisição das competências já mencionadas.

$O$ ensino na universidade constitui neste sentido, um processo de busca, de construção científica e de crítica ao conhecimento produzido. Corroborando as ideias de Pimenta e Anastasiou (2002: 164-165), algumas contribuições/características ser-lhe-ão exigidas:

1. Proporcionar o domínio de um conjunto de conhecimentos, métodos e técnicas científicos, que assegurem o domínio científico e profissional do campo específico, cujo ensino deve ser feito de forma crítica;

2. Conduzir a uma progressiva autonomia do aluno na busca de conhecimentos;

3. Considerar o processo de ensinar/aprender como actividade integrada à investigação;

4. Desenvolver a capacidade de reflexão;

5. Complementar a transmissão de conteúdos com um processo de investigação do conhecimento;

6. Integrar, vertical e horizontalmente, a actividade de investigação à actividade de ensinar do docente, o que supõe um trabalho em equipa;

7. Criar e recriar situações de aprendizagem; 
8. Valorizar a avaliação diagnóstica;

9. Conhecer o universo cultural e de conhecimentos dos alunos e desenvolver, com base nele, processos de ensino e aprendizagem interactivos e participativos.

Estas atribuições do ensinar e do aprender na universidade exigem uma acção docente diversa da tradicionalmente praticada. Na docência, o docente universitário necessitará de actuar como profissional reflexivo, crítico e competente no âmbito de sua(s) disciplina(s), além de estar capacitado a exercer a docência e empreender actividades de investigação. Neste sentido, torna-se fundamental a sua preparação numa área por vezes descurada - a pedagogia.

\section{CONCLUSÃO}

Parece não existirem dúvidas de que os próximos anos serão anos de decisões importantes para as instituições do ensino superior. Neste artigo, foram apresentados alguns dos desafios que se colocam, actualmente, à Universidade, de onde é possível concluir que perante as dificuldades de expansão e financiamento do sistema de ensino superior, a redução do número de alunos, as transformações inerentes ao Processo de Bolonha e à sociedade da informação e do conhecimento, a necessidade de novas formações baseadas na aquisição de competências e aptidões e da aprendizagem ao longo da vida, deverão existir naturalmente mudanças. A dúvida poderá residir na sua profundidade e no seu alcance. 


\section{Notas}

' A gestão do impacto destes problemas parece ser cada vez mais da responsabilidade das próprias instituições do ensino superior. Tal como refere Santiago (2000: 179), "a substituição de esquemas de regulação externa acentuada (controlo governamental) por esquemas de auto-regulação institucional (autonomia das Instituições de Ensino Superior - IES) mais orientada para as expectativas sociais pressupõe, de facto, uma responsabilização progressiva e mais clara das IES em dois domínios: i) monitorização e avaliação das actividades e resultados; ii) construção de dispositivos e desenvolvimentos de acções que sustentem as condições de desempenho e as mudanças necessárias. Com efeito, os critérios implícitos de qualidade, baseados numa auto-regulação implícita dos profissionais, vão sendo progressivamente substituídos por critérios explícitos a partir da confrontação de processos e resultados com as expectativas e representações sobre as funções e papéis das IES."

${ }^{2}$ Esta declaração, assinada pelos ministros da Educação da Alemanha, França, Itália e Reino Unido, tinha como principal motivação as reformas que estavam a ser introduzidas nos três primeiros países referenciados. "Essas reformas eram dirigidas à resolução de problemas associados a uma organização anquilosada dos respectivos sistemas do ensino superior, com formações iniciais longas, sem pontos intermédios de certificação, com uma diversificação de formações insuficiente face ao universo alargado de estudantes e, consequentemente, com taxas de repetição e abandono muito elevadas, provocando grandes desperdícios e frustrações nos estudantes e nas instituições. Os signatários da Declaração de Sorbonne, ao trazerem estas questões para a dimensão europeia, procuravam um respaldo externo para as reformas dificeis que pretendiam implementar nos seus países" (Simão, Santos \& Costa, 2002: 245).

${ }^{3}$ Esta declaração, para além de sublinhar o papel fundamental das universidades no desenvolvimento das dimensões culturais europeias, acentua a criação do espaço europeu do ensino superior como a chave para promover a mobilidade e a empregabilidade dos cidadãos. De referir que o conceito de harmonização de cursos, inscrito na Declaração de Sorbonne, é substituído pelo de convergência curricular na Declaração de Bolonha.

${ }^{4}$ A estes aspectos acresce a organização bienal de cimeiras ministeriais para acompanhamento e reorientação política. Assim, teve já lugar a Cimeira de Praga, em Maio de 2001, onde o número de países aderentes aumentou para 33, a Cimeira de Berlim, em 19 de Setembro de 2003, onde os Ministros decidiram aceitar os pedidos de adesão da Albânia, Andorra, Bósnia e Herzegovina, Santa Sé, Rússia, Servia e Montenegro, Former Yuguslavn Republic of Macedónia, ampliando o Processo para 40 países Europeus. A Cimeira de Bergen, na Noruega, teve lugar nos dias 19 e 20 de Maio de 2005 , onde foram re-assumidas as posições anteriores, entre as quais, o prazo de conclusão do processo de transição para o novo modelo de formação (ano de 2010) e a necessidade de fortalecer as universidades nos planos dos recursos e da qualidade.

${ }^{5}$ A promoção da mobilidade, ultrapassando obstáculos ao exercício efectivo da livre circulação, com particular atenção para: a) os estudantes, acesso a oportunidades de estudo e treino e serviços relacionados; b) os professores, investigadores e pessoal administrativo, reconhecimentos e valorização dos períodos passados num contexto europeu de investigação, ensino e treino, sem efeitos para os seus direitos de estatuto profissional. 
${ }^{6}$ Como diz Pedro Lourtie, em nome do grupo de follow-up de Bolonha, no relatório Furthering the Bologna Process (Praga, 2001), sobre a questão central de Bolonha da empregabilidade, e convergindo com as conclusões do seminário de Helsínquia, "o desenvolvimento de competências, aptidões e atitudes, tais como aptidões sociais, iniciativa, capacidade de resolução de problemas, capacidade de aprendizagem, são parte essencial do processo educativo. Em virtude das rápidas mudanças científicas e tecnológicas, que induzem alterações sociais e organizacionais, é cada vez mais difícil apontar o que será no futuro relevante para o mercado de trabalho e para o emprego. Os únicos valores seguros são uma educação científica larga e sólida, a capacidade de aplicar o conhecimento e de aprender ...".

7 "No seio das sociedades modernas, as instituições do ensino superior devem desenvolver-se como entidades autónomas que, de modo critico, produzem e transmitem a cultura através da investigação, do ensino e da aprendizagem. A Magna Carta de Bolonha aponta, assim, para que as universidades se abram cada vez mais às necessidades do mundo contemporâneo com independência de todo o poder político, económico e ideológico. Ao mesmo tempo, nas universidades e nos institutos politécnicos, a actividade didáctica deve ser indissociável da investigação, muito embora esta assuma características diferentes numas e noutras. A liberdade de criação cientifica continua a ser o princípio fundamental por que se rege a vida das universidades, pelo que os poderes públicos e os governos académicos devem garantir e promover o respeito por esta exigência, associada à missão institucional" (Simão, Santos \& Costa, 2002: 43).

${ }^{8} \mathrm{Na}$ Cimeira de Berlim, os Ministros, conscientes da necessidade de promover vínculos mais estreitos entre a Área Europeia do Ensino Superior (AEES) e a Área Europeia de Investigação (AEI) numa Europa de Conhecimento, bem como da importância da investigação como parte integrante do ensino superior pela Europa, consideraram necessário ir além do enfoque presente em dois ciclos principais de Ensino Superior e incluir o doutoramento como o terceiro ciclo no Processo de Bolonha. Enfatizaram, assim, a importância da investigação, do treino em investigação e da promoção da interdisciplinaridade na manutenção e melhoria da qualidade do ensino superior e, genericamente, no aumento da competitividade do ensino superior Europeu. Os Ministros apelaram para o aumento da mobilidade ao nível do doutoramento e pós-doutoramento e incentivaram as respectivas instituições para aumentarem a sua cooperação em estudos para doutoramento e no treino de jovens investigadores.

${ }^{9}$ Os currículos devem ser construídos tendo em vista a articulação das várias disciplinas que o constituem e a sua pertinência no actual contexto profissional.

${ }^{10}$ No ano lectivo de 2006/2007, os cursos ministrados na Universidade Católica já estarão organizados de acordo com as recomendações do Processo de Bolonha.

${ }^{11} \mathrm{O}$ sistema de créditos ECTS, que tem vindo a ser introduzido em diversos países europeus, parte assim de um novo paradigma de aprendizagem, medindo a "carga de trabalho" do estudante definida em termos dos objectivos da aprendizagem - a aquisição de conhecimentos e competências. O estudante é, assim, retirado da periferia do processo educativo para passar a ser o centro do processo de aprendizagem, o que é mais consentâneo com o carácter policêntrico que deve caracterizar a instituição do ensino superior. O número de créditos ECTS correspondente a um ano curricular é sempre de 60 créditos, independente da forma como o ensino está organizado (com mais ou menos aulas presenciais e com maior ou menor integração horizontal do currículo) (Simão, Santos \& Costa, 2002: 164-165). 
12 De acordo com Castro $\left({ }^{2} 2000\right.$ : 166-167), as transformações aceleraram-se com a segunda revolução industrial, que implicou um conjunto de inovações tecnológicas tornando possível a transição de uma economia baseada no artesanato à manufactura, criando as condições para uma economia moderna. Uma das maiores transformações ocorreu no campo das organizações e de sua gestão. O surgimento da Organização Científica do Trabalho e, mais tarde, o princípio da linha de montagem, bem como as ideias de Fayol constituíram-se em movimentos que revolucionaram as organizações e influenciaram de modo definitivo o pensamento gerencial. Particularmente, a Administração Científica foi uma resposta à necessidade de técnicas que visassem reduzir os níveis de desperdício da indústria da época, ocasionados por actos errados e ineficientes.

Porém, enquanto este modelo permanecia intocável nas organizações, paralelamente a sociedade começava a ingressar em novos ciclos de inovação tecnológica, comércio internacional intenso, restrições energéticas e mudanças radicais nos hábitos e exigências dos consumidores, que definiram um quadro de profunda turbulência para as organizações.

A emergência de um novo paradigma organizacional é, assim, fruto de uma nova ordem mundial em gestação, que inclui inovações tecnológicas, novas dimensões geopolíticas e a construção de grandes superfícies comerciais, que tendem a favorecer os países membros no crescimento económico e na competitividade internacional.

Neste contexto, a velha organização piramidal, formalista e rígida mostra as suas debilidades. A flexibilidade passa a ser uma característica da organização competitiva. Resumidamente, e segundo ainda J. M. Castro ( $\left.{ }^{2} 2000\right)$, as tendências do contexto mundial são: a globalização da economia e novos padrões de competição; os efeitos da tecnologia sobre a competitividade; os efeitos da tecnologia sobre o emprego; o aumento da participação dos serviços na economia.

Estas tendências estão a provocar uma série de impactos nas organizações, nomeadamente sobre as estratégias, as estruturas e sobre o perfil do gestor. Assim, é possível afirmar que as organizações actuais tendem a inclinar-se para modelos mais flexíveis que possibilitem contínuas readaptações dos seus recursos humanos, tecnológicos e financeiros. Somente uma organização aberta, inovadora e adaptativa permitirá melhorias contínuas na qualidade final dos produtos, aumento na satisfação dos seus públicos diversos (clientes, accionistas, funcionários, fornecedores) e, consequentemente, maior produtividade e competitividade.

Considerando que as instituições do ensino superior procuram estar, de alguma forma, à frente dessas mudanças, principalmente no que concerne à produção e transmissão desse conhecimento e diante da responsabilidade na transformação da sociedade através da educação, é preciso, neste momento, reflectir como poderá ser o seu processo de auto transformação diante do cenário que se afigura.

${ }^{13}$ Trata-se de um outro desafio colocado pela sociedade do conhecimento - a formação ao longo da vida, que se traduz no acolhimento de novos "públicos" com necessidade de novas formações. Segundo Correia (2001: 1), "as Universidades, na Economia do Conhecimento, estão num processo de redefinir a sua missão e funções, os seus modelos de poder, de organização e de gestão, a natureza das suas actividades e as práticas utilizadas". 


\section{BIBLIOGRAFIA}

Araújo, J. (2002). Bolonha: Oportunidade histórica. In A Universidade Portuguesa - Um debate necessário [On-line], Disponível http: http://pwp.netcabo.pt/0225914001/araujo.htm

Castro, J. M. (2000). Qualidade total em educação: Perspectivas e controvérsias. In D. A. Moreira (Org.), Didática do Ensino Superior . Técnicas e Tendências ( $2^{\mathrm{a}}$ ed., pp. 165-180). São Paulo: Editora Pioneira.

Correia, A. (2001). O ensino ao longo da vida e os novos desafios para a Universidade: Algumas reflexões. Comunicação apresentada na $2^{\mathrm{a}}$ Conferência Internacional de Tecnologias de Informação e Comunicação na Educação. Braga: Universidade do Minho.

Delors, Jacques et al. (1999). Educação um tesouro a descobrir. Relatório para a UNESCO da Comissão Internacional sobre Educação para o século XXI ( $5^{a}$ ed.). Lisboa: Edições Asa.

Haug, G. (2001). Significado da Declaração de Bolonha de junho de 1999. In Revista Millenium, 21 [Online]. Disponível http:

http://www.ipv.pt//millenium/Millenium21/21.pt3.htm

Lourtie, P. (2001). Relatório encomendado pelo grupo de acompanhamento do Processo de Bolonha [Online]. Disponível http:

http://campus.sapo.pt/print/7C324/348067.html

Parecer Geral da Universidade Católica Portuguesa sobre a Declaração de Bolonha (s.d.) [Online]. Disponível http: http://www.ucp.pt/Parecer.htm

Pimenta, S. G., \& Anastasiou, L. G. C. (2002). Docência no ensino superior. Colecção Docência em Formação (Vol. 1). São Paulo: Editora Cortez.

Pinto, C. A. (2003). Ensino superior - participar na mudança. In Jornal da FNE, Ano XIV, 4, 10-11.

Revista do Sindicato Nacional do Ensino Superior (2002). Bolonha não é um tratado, 2, 10-13.

Santiago, R. A. (2000). Aprendizagem organizacional nas instituições de ensino superior. In J. Tavares \& R. A. Santiago (Orgs.), Ensino Superior. (In)sucesso Académico (pp. 177-206). Porto: Porto Editora.

Schutte, J. G. (2002). Virtual teaching in higher education: The new intellectual superhighway or just another traffic jam? Northridge: California State University.

Simão, J. V., Santos, S. M., \& Costa, A. A. (2002). Ensino superior: Uma visão para a próxima década. Lisboa: Editora Gradiva. 